\title{
Comparison of the Effect of Misoprostol and Evening Primrose oil Capsules with Misoprostol on Delivery Method in Post-Term Pregnancy: Clinical Trial
}

\author{
Soma Bahmani ${ }^{1 *}$, Ronak Shaoei ${ }^{2}$
}

1. Instructor, School of Nursing and Midwifery, Kurdistan University of Medical Sciences, Sanandaj, Iran

2. Associate Professor, Clinical Care Research Center, Kurdistan University of Medical Sciences, Sanandaj, Iran

\begin{tabular}{|c|c|}
\hline Article Info & ABSTRACT \\
\hline $\begin{array}{l}\text { Received: 2020/06/25; } \\
\text { Accepted: 2021/01/04; } \\
\text { Published Online: 2021/09/21 } \\
\text { dof } 10.30699 \text { /ajnmc.29.3.181 }\end{array}$ & $\begin{array}{l}\text { Introduction: Introduction: Post-term pregnancies are pregnancies that last more than } 42 \\
\text { full weeks ( } 294 \text { days) from the first day of the last menstrual period. With increasing gestational } \\
\text { age, the rate of maternal and fetal morbidity and mortality significantly increases. Among } \\
\text { medical methods, misoprostol is widely used to prepare the cervix in post-term pregnancies. But } \\
\text { today, due to the high side effects of misoprostol, especially the increasing need for cesarean } \\
\text { section, some complementary medicine methods are used to prepare the cervix. The aim of this } \\
\text { study was to compare the effect of Misoprostol and Evening primrose oil capsule with } \\
\text { Misoprostol on delivery method in post-term pregnancies. }\end{array}$ \\
\hline
\end{tabular}

Original Article

Use your device to scan and read the article online

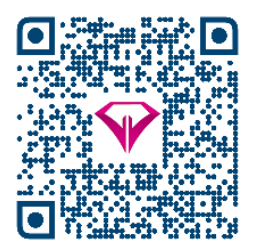

Methods: This study was performed as a single-blind randomized clinical trial on 130 pregnant women with post-term pregnancy referring to the delivery ward of Besat Hospital in Sanandaj, Iran. The samples were selected by available sampling method and assigned to the intervention and control groups by random sampling method. In the intervention group, a 500 $\mathrm{mg}$ capsule of evening primrose oil was given vaginally and 25 micrograms of misoprostol were given sublingually, and in the control group, an ineffective capsule was given vaginally with 25 micrograms of misoprostol sublingually. Demographic data, clinical characteristics and delivery method were used for data collection. Data were analyzed by SPSS software version 21 and statistical tests such as Chi-square, t-test and ANOVA. P-value less than 0.05 was considered significant.

Results: Findings showed that there was no significant difference between the two groups in terms of demographic and midwifery characteristics and the two groups were homogeneous in this respect $(P$ value $>0.05)$. But in the evening primrose oil and misoprostol group, the mean bishop score was significantly increased compared to the misoprostol group $(P$ value $<0.05)$. Also, in the evening primrose oil and misoprostol group (12.3\%), the need for cesarean section was lower than placebo and misoprostol group $(41.5 \%)(P$ value $<0.0001)$.

Conclusion: The results of the study showed that the use of vaginal capsules of evening primrose oil with misoprostol compared to misoprostol alone while helping to ripening the cervix is associated with a lower rate of cesarean section.

Keywords: Complementary medicine, Misoprostol, Post-term pregnancy, Delivery method

Corresponding Information:

Soma Bahmani, Instructor, School of Nursing and Midwifery, Kurdistan University of Medical Sciences, Sanandaj, Iran. Email: soma.bahmani25@gmail.com

Copyright $\odot$ 2021, This is an original open-access article distributed under the terms of the Creative Commons Attribution-noncommercial 4.0 International License which permits copy and redistribution of the material just in noncommercial usages with proper citation.

\section{How to Cite This Article:}

Bahmani S, Shaoei R. Comparison of the Effect of Misoprostol and Evening Primrose oil Capsules with Misoprostol on Delivery Method in Post-Term Pregnancy: Clinical Trial. Avicenna J Nurs Midwifery Care. $2021 ; 29$ (3) :181-189 
مقايسة تأثير ميزويروستول و كِيسول روغن گَل مغربى با ميزويروستول بر روش زايمان در حاملكىهاى يس از

\author{
موعد: يك كار آزمايى بالينى باليز

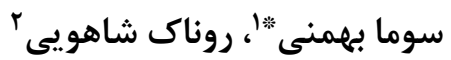

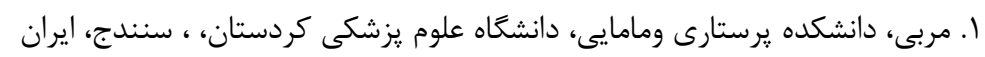

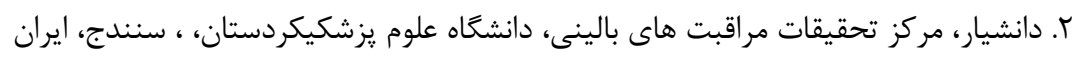

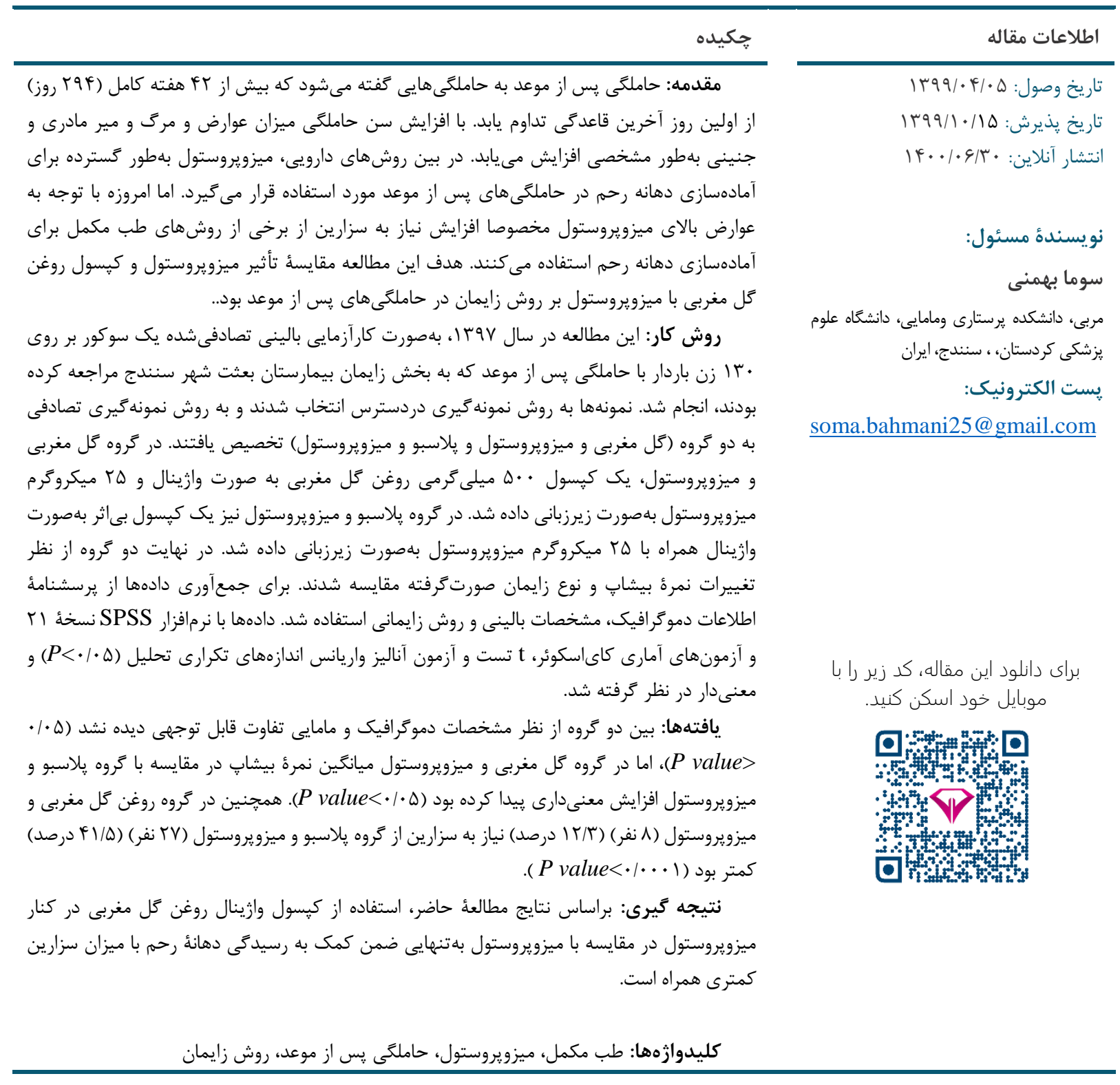

مقدمه

مامايى و زايمان مداخله و ارزيابى در حاملگىهاى يس از موعد

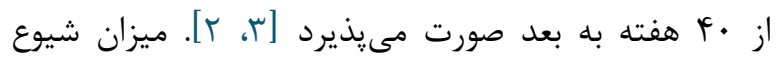

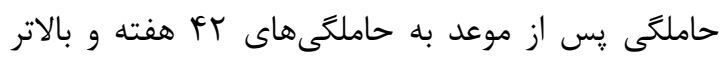
اطلاق مىشود [ [ ]، اما براساس راهنماى كشورى ارعائه خدمات 
مكونيوم"'، تاكى كاردى" همراه با اثرات نامطلوب بر ضربان

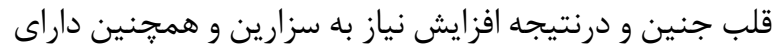

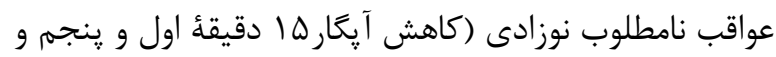

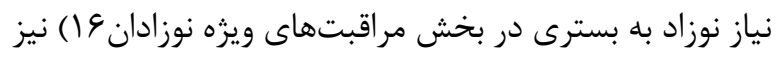

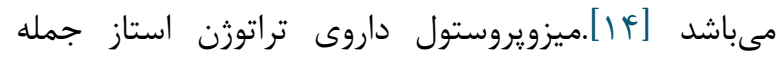
اختلالات مرتبط با آن مىتوان به نواقص جمجمهاى،

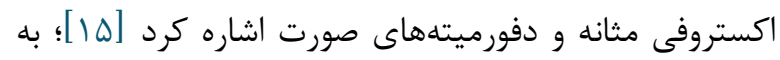

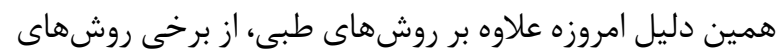

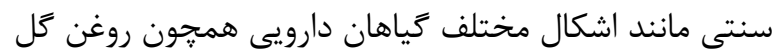

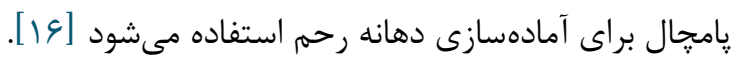

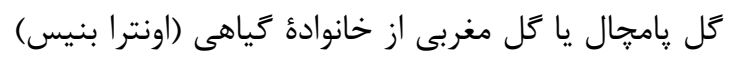
است [IV] روغن كل مغربى از دانههاى اين كياه استخراج

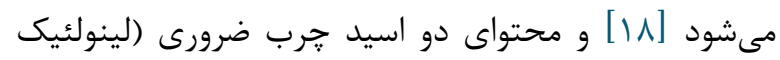

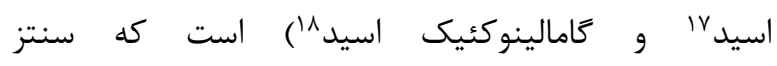
يروستاكلاندين ميزويروستول را تسهيل مى كند و منجر به نرم

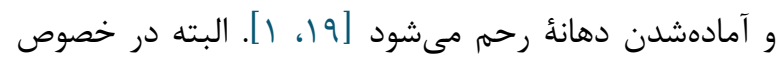

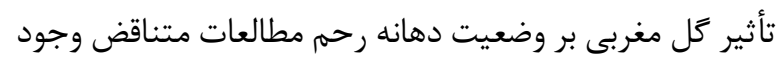
دارد. براساس يزوهش Tahermanesh و همكاران، كيسولهاى

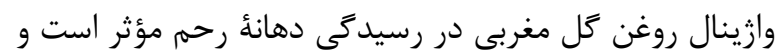

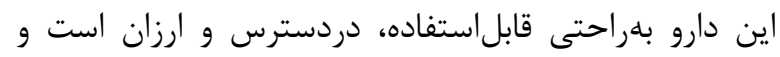

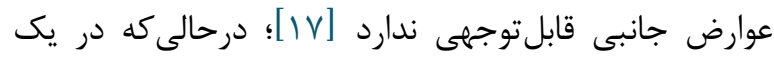
مطالعُ كذشتهنكر كزارش شد كه مصرف خوراكى روغن گل

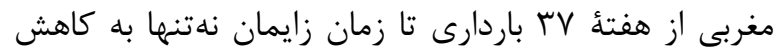

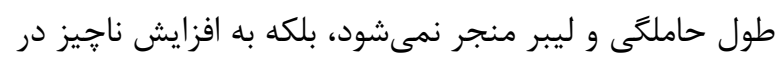
شيوع :اركى طولانىمدت بردههاى جنينى، تقويت انقباضات

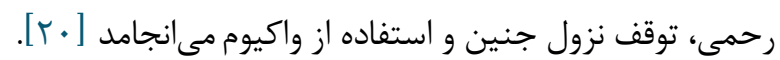

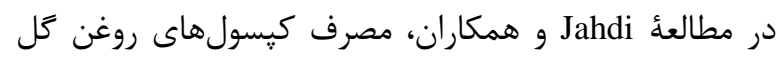
مغربى تغيير قابل توجهى در نمرءٔ بيشاض ايجاد نكرده بود

در مطالعات مختلف گزارش شده است كه مصرف كل

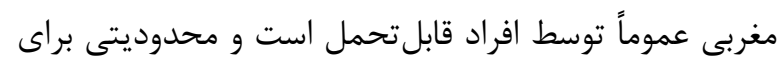

حاملكىهاى يس از موعد ثَ تا 19 درصد است. اكرجه

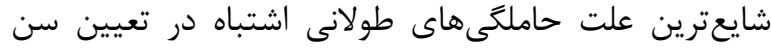

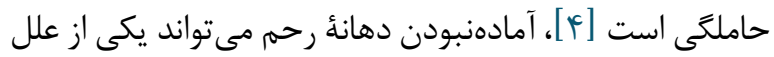

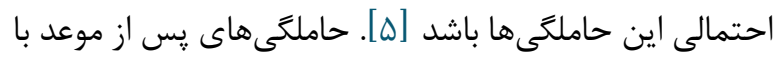
خطرات متفاوتى مانند صدمات فيزيكى ناشى از وضع حمل نوزاد درشت، خونريزى و عفونت يس از زايمان و بسترىشدان إنان

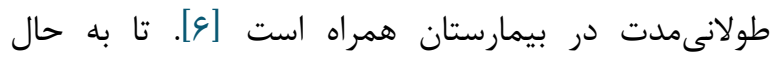
روشهاى متعددى براى كمك به نرمشدن دهانئ رحم و

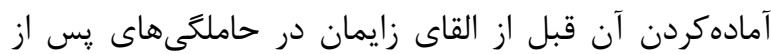

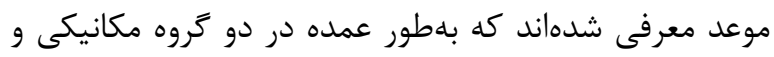

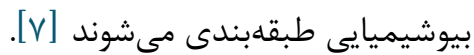
از تكنيكهاى مكانيكى مىتوان به كاتتر ترانس سرويكال'

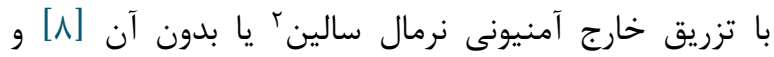

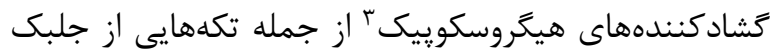

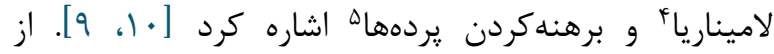

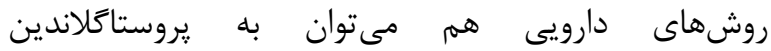

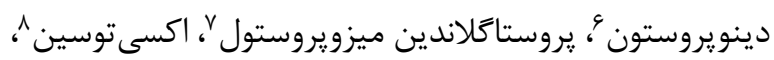

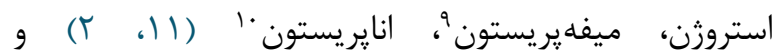

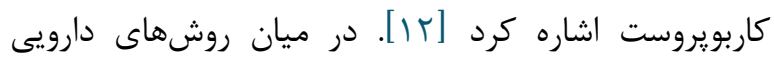

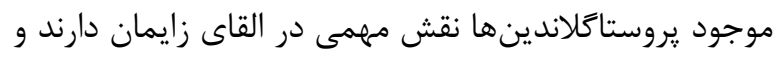
منقبضكنندة رحم محسوب مىشوند. همجنين در هر

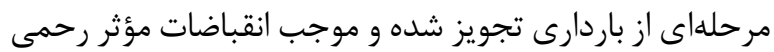

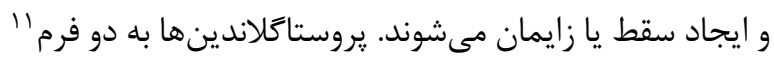

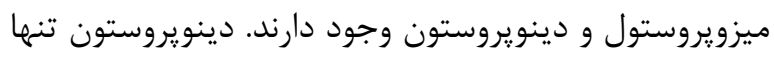

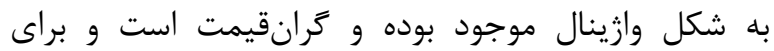
نتحهدارى نياز به يخجال دارد، اما ميزويروستول هم بهصورت

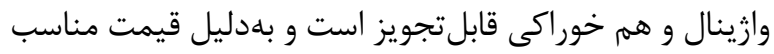
و تأثير بالاى آن بهطور كسترده براى القاى زايمان استفاده

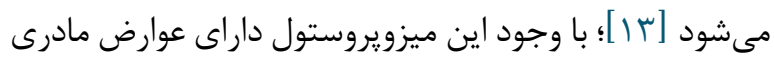
و جنينى بسيارى است؛ از جمله تهوع، استفراغ، سردرد، اسهال،

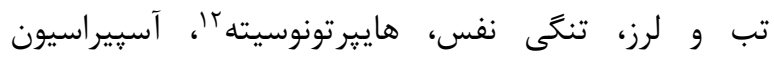

1. Transcervical Catheter

2. Normal Saline

3 . Hygroscopic

4. Laminaria

${ }^{5}$. Striping

${ }^{6}$. Dinoprostone

7. Misoprostol

${ }^{8}$. Oxytocin

${ }^{9}$. Mifepristone

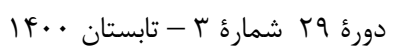


با اطمينان هو درصد و توان آزمون •1 درصد در هر كروه 9D نفر محاسبه شد. روش نمونه گيرى دردسترس بود كه به روش تصادفى زرتاب سكه به كروهها تخصيص داده شد. روش

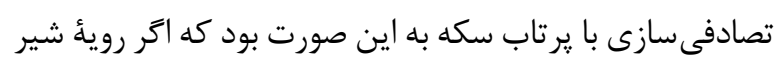

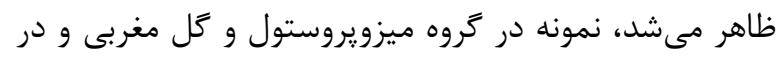

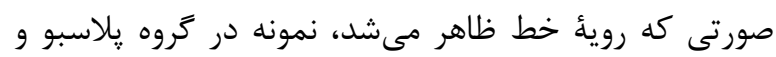

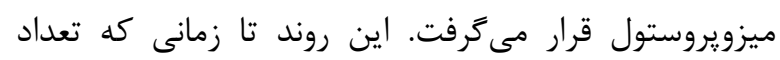

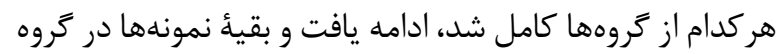
مقابل قرار كرفتند.

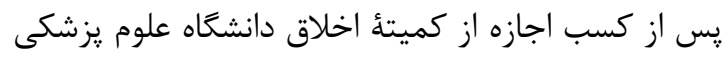

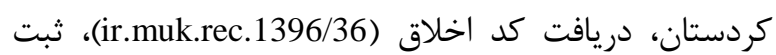

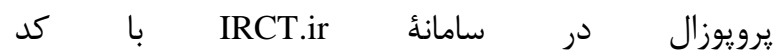
و و كسب معرفىنامه از معاونت يزوهشى دانشكدة يرستارى و مامايى و ارائٔة آن به رئيس مركز

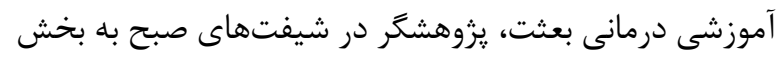

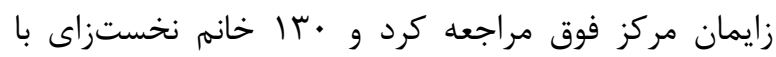

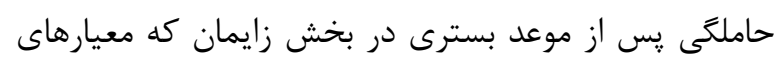

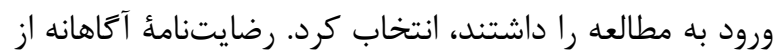

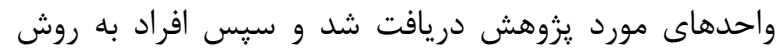

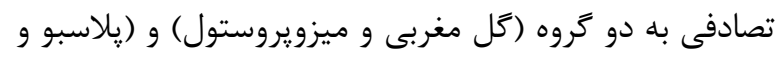
ميزويروستول) تخصيص داده شدند. ابزار جمع آورى اطلاعات يرسشنامهُ سلفقمتى بود: قسمت اول به مشخصات دمو مرافيك مادر (سن، تحصيلات، شغل، محل سكونت)، قسمت دوم به مشخصات مامايى (تعداد سقط،

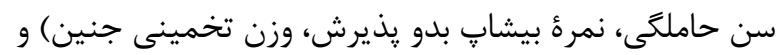

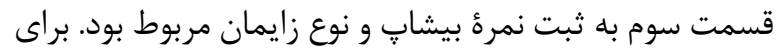

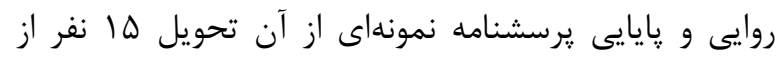

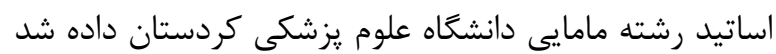

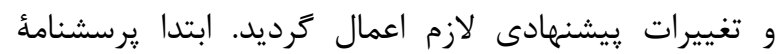

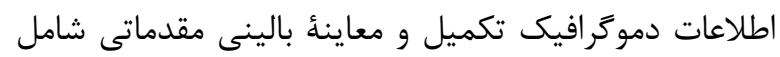

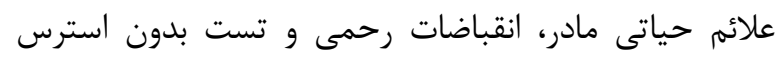
جنين براى تمامى نمونهها توسط همكار يزوهشى ارزيابى شادي شد.

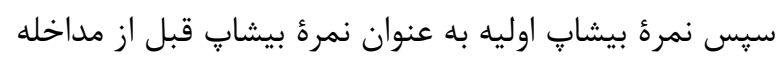

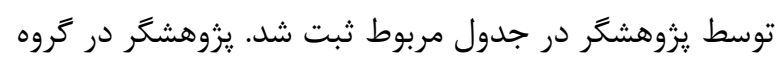

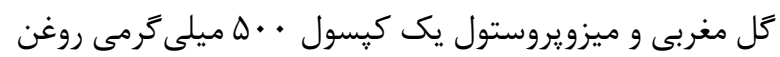

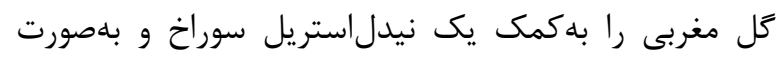

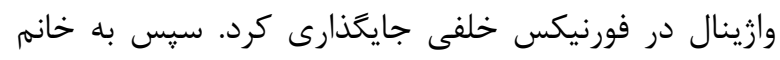

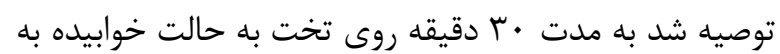

استفاده از آن در دوران باردارى وجود ندارد. همجنين سبب

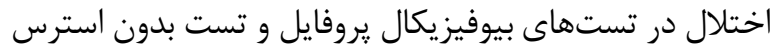

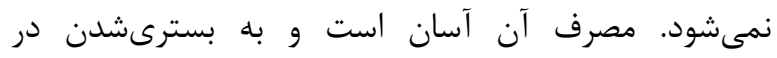

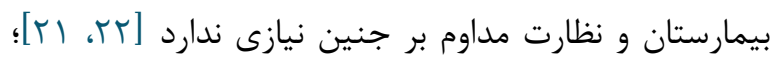
بنابر اين با توجه به عوارض جانبى در استفاده از ميزويروستول،

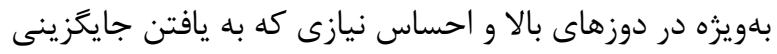

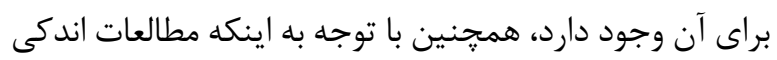

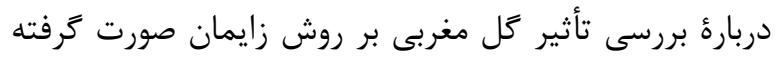

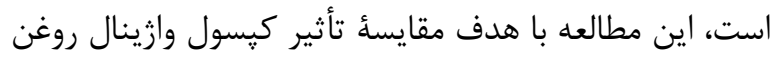

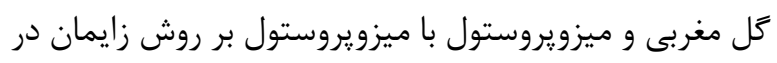
خانمهاى با حاملكى يس از موعد در بخش زئس زايمان بيمارستان بعثت سنندج در سال Vو با انجام شده است.

$$
\text { روش كار }
$$

اين يزوهش يك مطالعه كار آزمايى بالينى تصادفىشده يك رون

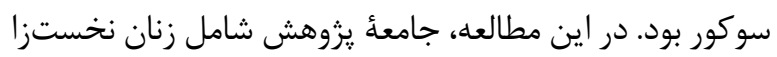

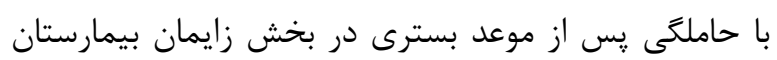

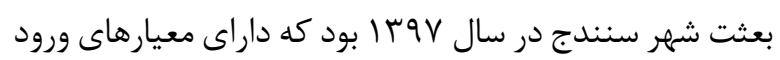
به مطالعه بودند. معيارهاى ورود به مطالعه عبارت بودند ازئ

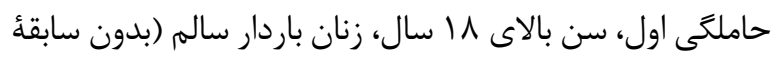

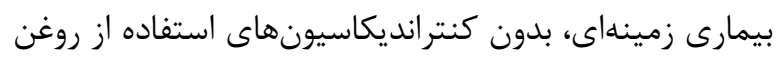

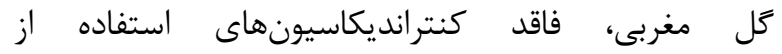

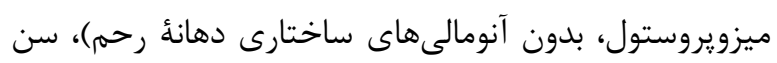

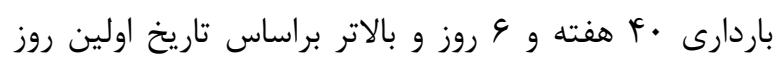

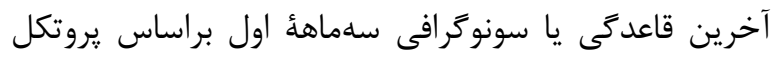

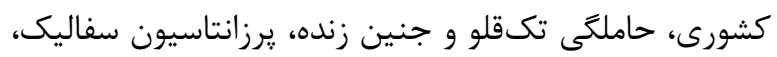

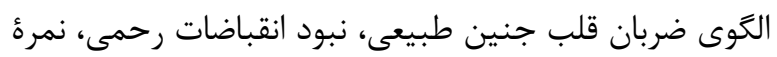

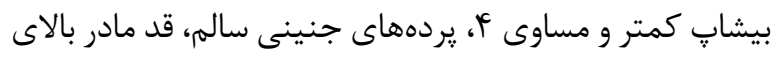

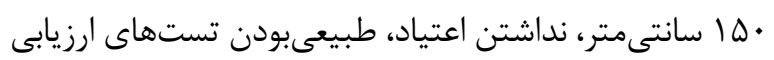

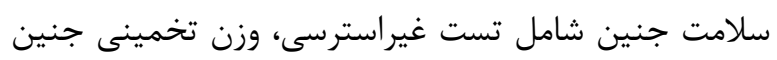

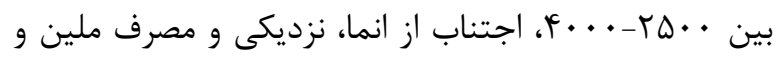

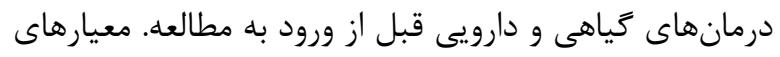

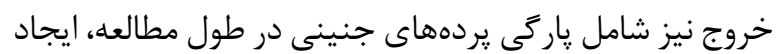

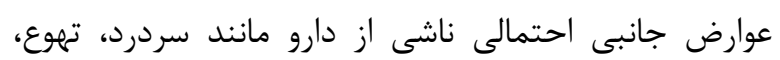

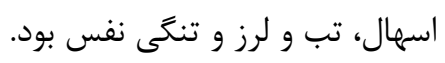

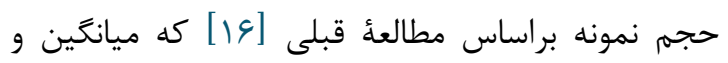

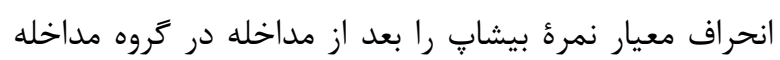
أح I/VD 
مستقل، آناليز كوواريانس، آناليز واريانس يكطرفه اندازههاى تكرارى تجزيه و تحليل شد و دو گروه براساس نتايج حاصل از قسمت سوم يرسشنامه از نظر روش زايمان با يكديخر مقايسه شدند.

\section{بافتهها}

براساس يافتههاى يثوهش، ميانگين سنى در گروه گل

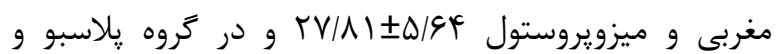

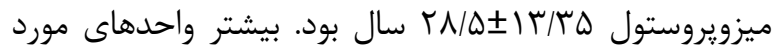
يزوهش (N/D/D درصد) مدرك دييلم داشتند و شغل بيشتر آنها (r/A)

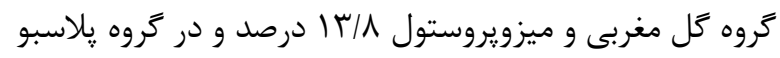

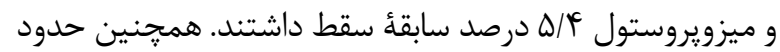

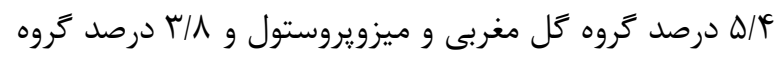
يلاسبو و ميزويروستول سابقه كورتاز را ذكر كردند. همجنين

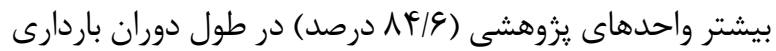

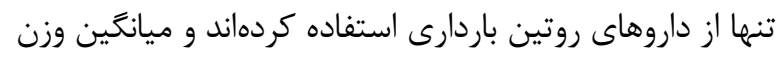

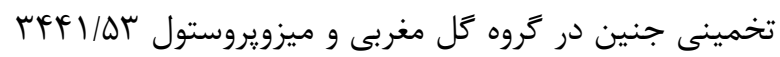

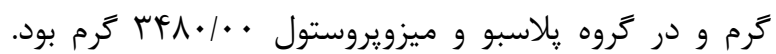
براساس نتايج حاصل دو گروه از نظر مشخصات فردى همگن

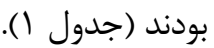

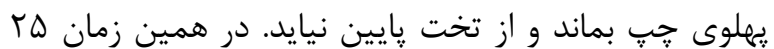
ميكروگرم ميزويروستول نيز بهصورت زيرزبانى به مادر داده

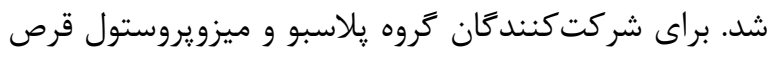

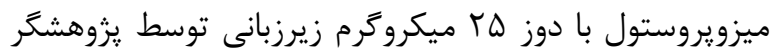

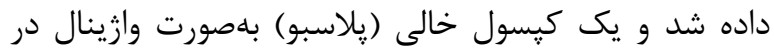
فورنيكس خلفى جايگذارى و سيس به خانم توصيه شد به به به به

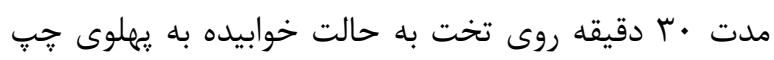
بماند و از تخت يايين نيايد. در هر دو گروه، در ساعت اول ضربان قلب جنين هر ها دقيقه يكبار توسط يروهشگر ارزيابى نه

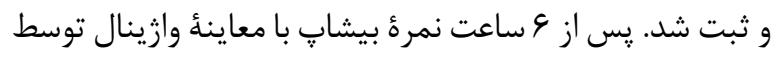

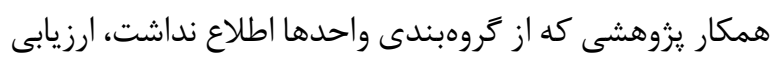
و توسط يزوهشگر در جدول مربوط ثبت شد. اخر نمرهٔ بيشاب

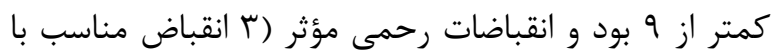
طول مدت • c ثانيه) شروع نشده و الكوى ضربان قلب جنين طبيعى بود، مداخله حداكثر تا دو دوز ديخر به فاصله هر 9

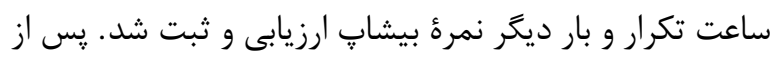

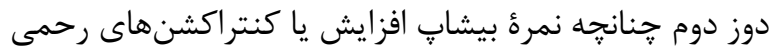
شروع مىشد، دوز سوم اعمال نشد و مداخله پيايان مىيافت.

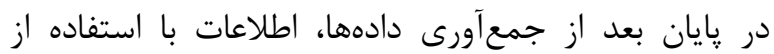
نرمافزار آمارى SPSS Inc., Chicago, Ill., USA) SPSS نسخd ال با استفاده از آزمونهاى آمارى كاى كاى اسكوئر، t تست

\section{جدول ا. مشخصات فردى واحدهاى مورد يزوهش}

\section{مشخصات}

\begin{tabular}{|c|c|c|c|c|}
\hline p-value & (يلاسبو وميزويروستول) & (كل مغربى وميزويروستول) & & \\
\hline \multirow{5}{*}{$\cdot N r$} & (r & )$\backslash, \Delta(1$ & $<19$ & \multirow{5}{*}{ سن } \\
\hline & ) $K F / q(19$ & )$r \cdot / q(r \cdot$ & $T Y-T$. & \\
\hline & 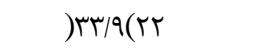 & )$r q / 4(19$ & $r q-r \Delta$ & \\
\hline & )$r v / N(1 \Lambda$ & ) & $r F-r$. & \\
\hline & ) $1 \cdot 1 \Delta(V$ & ) $\mid r / T(\Lambda$ & $>r_{\Delta}$ & \\
\hline \multirow{5}{*}{$\cdot \pi V$} & ) $1, \Delta(1$ & )$\pi / 1(r$ & بىسواد & \multirow{5}{*}{ تحصيلات مادر } \\
\hline & ) & )$r / r 9(19$ & ابتدايى & \\
\hline & ) $\operatorname{Irr}(\Lambda$ & )$Y Y / 9(19$ & 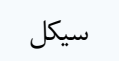 & \\
\hline & )$F \cdot / \cdot(r \varepsilon$ & ) $r g / q(r F$ & دييلم & \\
\hline & ) $1 \% / 9(9$ & )$\xi / r(F$ & دانشعاهى & \\
\hline.$/ 49$ & $\begin{array}{l}) q T / \Gamma(\varepsilon . \\
) V / V(\Delta\end{array}$ & $\begin{array}{c}) q \Delta / \mathcal{F}(\varepsilon T \\
) \mathcal{F} / \mathcal{G}(r\end{array}$ & خاغل دار & شغل مادر \\
\hline$\cdot \pi \Delta$ & $\begin{array}{l}) V N D(\Delta I \\
) Y M / \Delta(\mid K\end{array}$ & $\begin{array}{l}) \& \backslash / \Delta(Y \cdot \\
) r N \Delta(T \Delta\end{array}$ & روستا & محل سكونت \\
\hline
\end{tabular}




\begin{tabular}{|c|c|c|c|c|}
\hline \multicolumn{3}{|c|}{ تعداد (درصد) } & \multirow[b]{2}{*}{$\begin{array}{c}q \pm F \cdot-F_{1} \\
>F_{1}\end{array}$} & مشخصات \\
\hline$\cdot 190$ & $\begin{array}{l}) \wedge F / \varepsilon(\Delta \Delta \\
) \backslash \Delta / r \wedge(1 .\end{array}$ & $\begin{array}{l}) \wedge r / \cdot V(\Delta F \\
) \mid \varepsilon / 9 r(11\end{array}$ & & سن حاملكى \\
\hline$\cdot / 1$ & $\begin{array}{c})) \cdot / \wedge(\vee \\
) \wedge q / Y(\Delta \Lambda\end{array}$ & $\begin{array}{l}) T V / V(I \Lambda \\
) V T / K(F V\end{array}$ & خير & سابقه سقط \\
\hline$\cdot \mid \Delta F$ & $\begin{array}{l}) V / N(\Delta \\
) \operatorname{qrT}(\varepsilon .\end{array}$ & $\begin{array}{c}) \backslash \cdot / \wedge(\vee \\
) \wedge q / \Gamma(\Delta \wedge\end{array}$ & خير & سابقه كورتاز \\
\hline
\end{tabular}

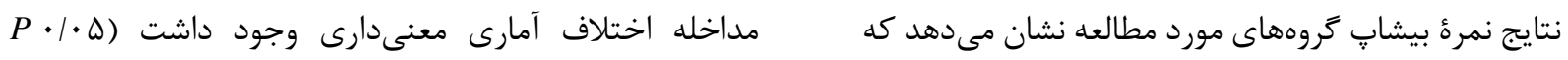

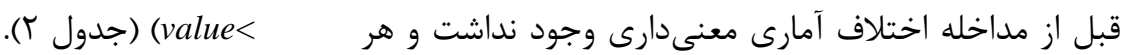

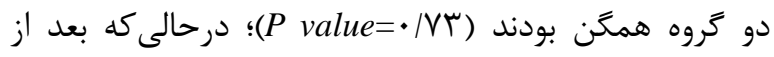

جدول r. مقايسهُ ميانگين و انحراف معيار نمرهُ بيشاب گروههاى مورد مطالعه

\begin{tabular}{|c|c|c|c|}
\hline p-value & هِاسبو و ميزويروستول & كل مغربى و ميزويروستول & نمره \\
\hline$\cdot / N^{\mu}=\mathrm{P}$ value & $\cdot 199 \pm \cdot 190$ & $\cdot|f| \pm \cdot|Q|$ & 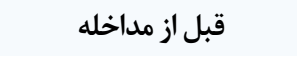 \\
\hline $\mathrm{p}$ value $<\cdot / \cdot \Delta$ & $|/ 4| \pm \cdot N q$ & $T / N \Delta \pm I / T \Lambda$ & وساعت اول بعد از مداخله \\
\hline $\mathrm{p}$ value $<\cdot / \cdot \Delta$ & $r / \cdot \Lambda \pm I N r$ & $\Delta / \cdot \Lambda \pm 1 / q \zeta$ & و ساعت دوم بعد از مداخله \\
\hline
\end{tabular}

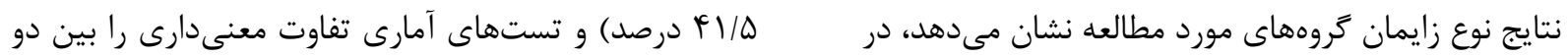

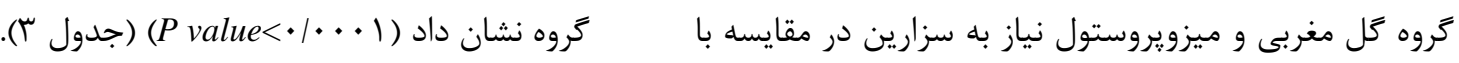

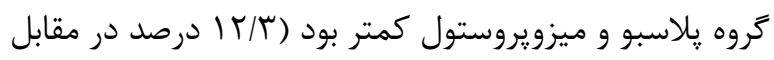

جدول r. مقايسةُ نوع زايمان در تروههاى مورد مطالعه

\begin{tabular}{|c|c|c|c|}
\hline \multirow{2}{*}{ p-value } & \multicolumn{2}{|c|}{ فراوانى (درصد) } & \multirow{2}{*}{ روش زايمان } \\
\hline & يلاسبو و ميزويروستول & كل مغربى و ميزويروستول & \\
\hline \multirow{2}{*}{$\cdot 1 \cdots \cdot 1$} & )$\Delta N / \kappa \xi(\Gamma \Lambda$ & )$\wedge V / \& 9(\Delta V$ & طبيعى \\
\hline & )$F / / \Delta T(Y V$ & ) $\mid r K \cdot(\Lambda$ & سزارين \\
\hline
\end{tabular}

از اين نظر كاملاً همَن بودند؛ بنابراين با همسانبودن اين

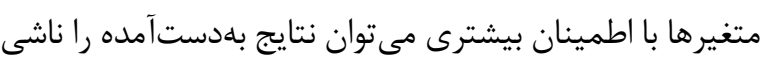

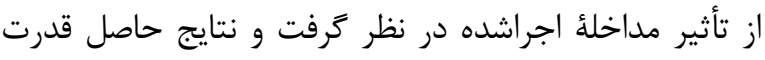

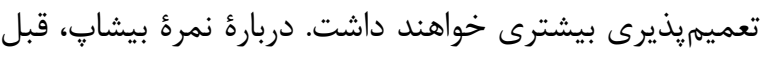

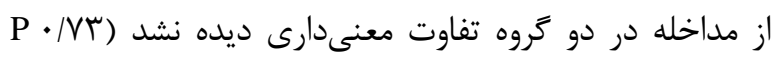
(value=

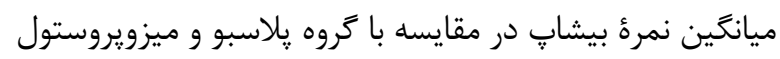

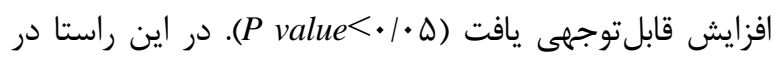

مطالعهٔ حاضر با هدف مقايسٔ تأثير ميزويروستول و كيسول

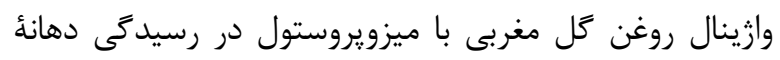

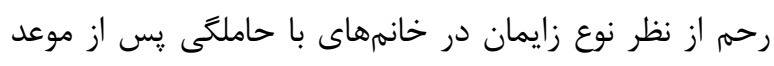

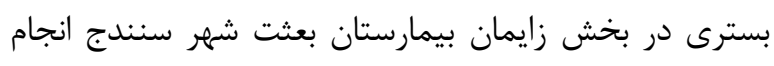

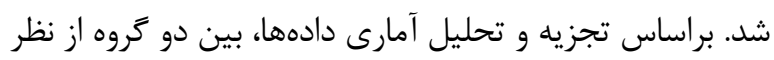

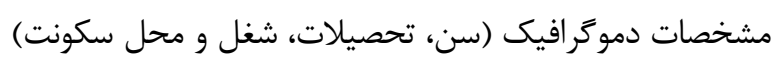

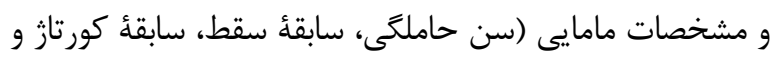

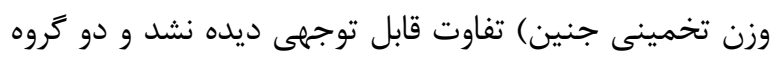

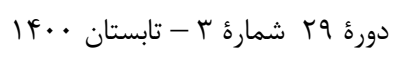

$$
\text { مجله مراقبت يرستارى و مامايى ابنسينا }
$$




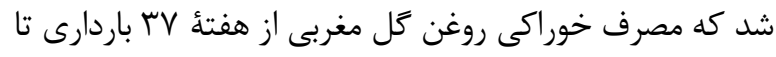

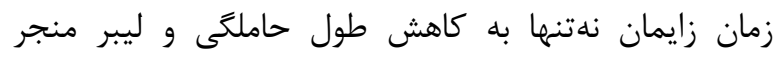

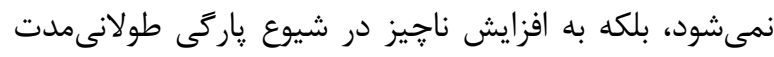

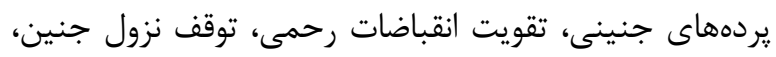

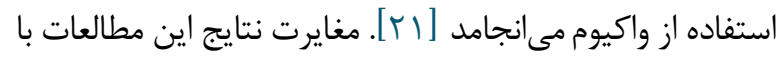

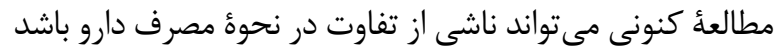

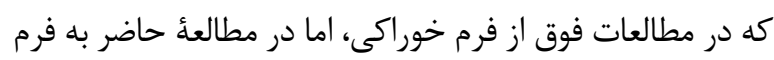

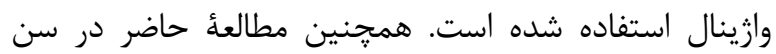

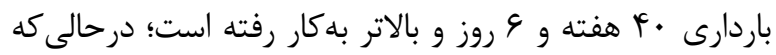

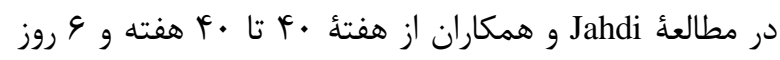

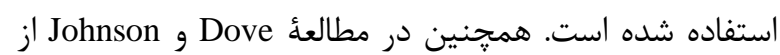
هفته VT باردارى تا زمان شروع ليبر به كار رفته است.

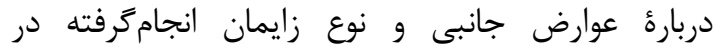

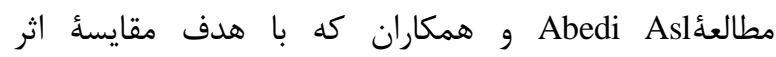

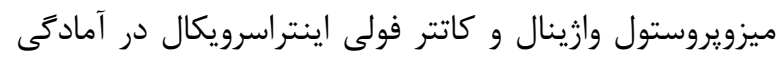
دهانهُ رحم قبل از القاى زايمان صورت كرفت، كزارش شد كد كه

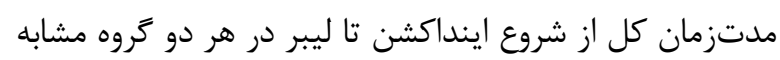

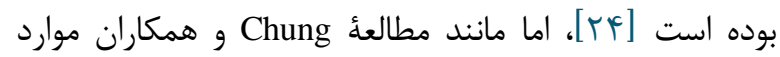
هاييراستيموليشن، تاكى سيستول، نياز به سداتيو (يتدين،

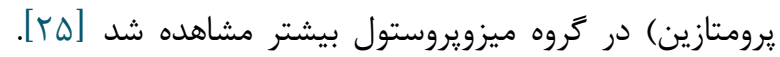

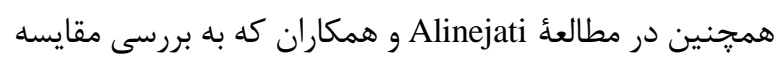

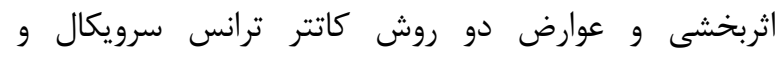

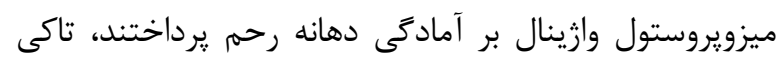

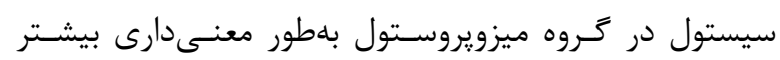

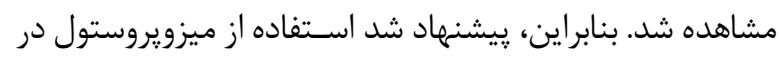
مواردى كه احتمال تاثير سوء تاكى سيستول بيشـتر است (مثلا

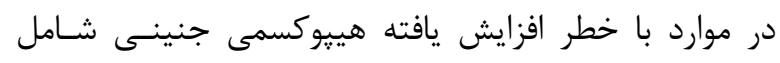

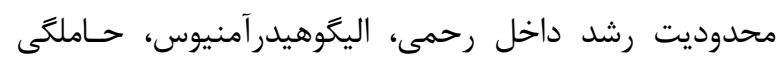

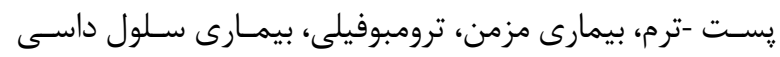

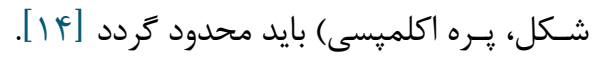

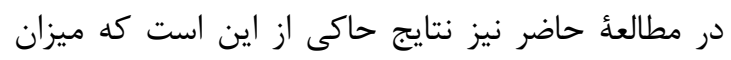

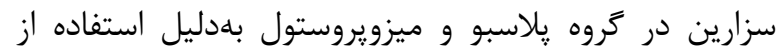

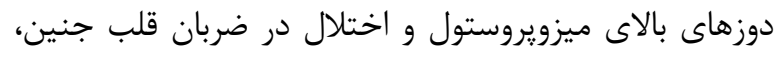

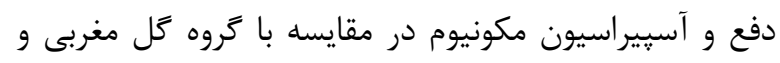

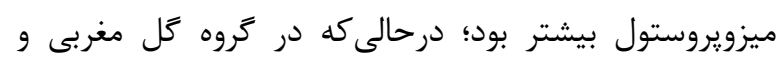

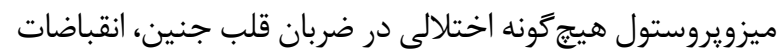

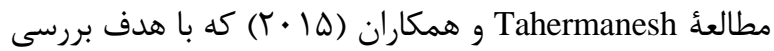
تأثير روغن گل مغربى بر رسيدگى سرويكس و ديلاتاسيون دهانئ

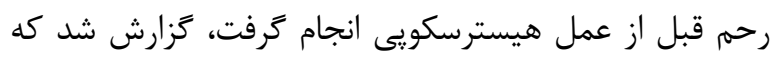

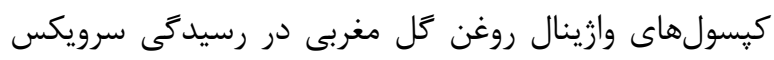

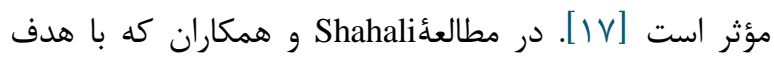

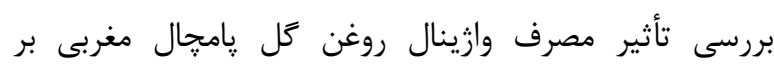

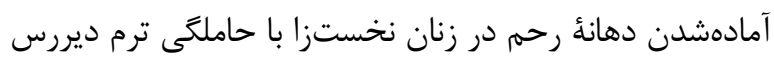

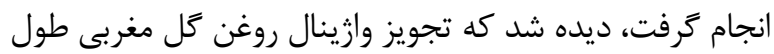

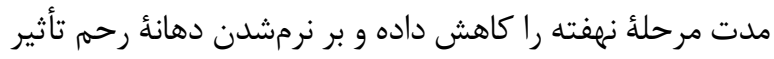

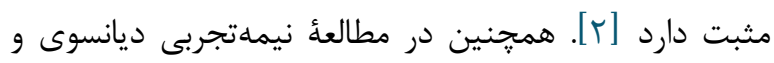

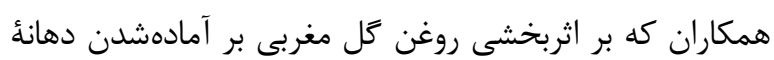

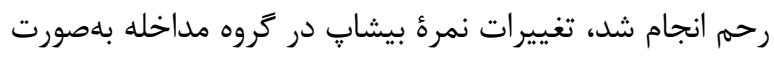

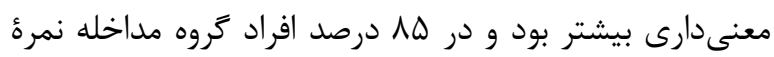

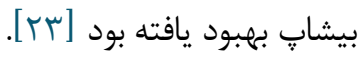
نتايج اين سه مطالعه نيز در راستاى نتايج مطالعهُ كنونى و

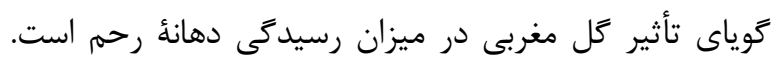

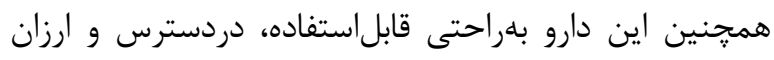

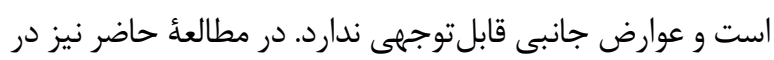

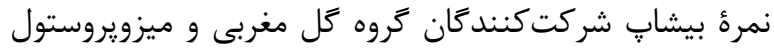

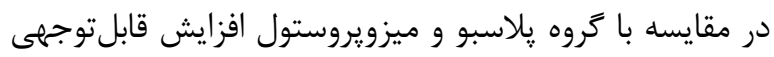

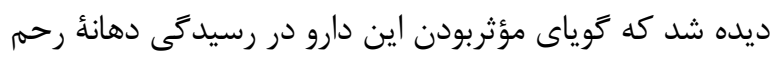

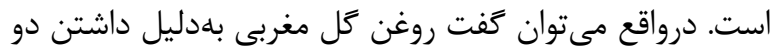
اسيد جرب ضرورى (لينولئيكاسيد و كامالينوكئيك اسيد)

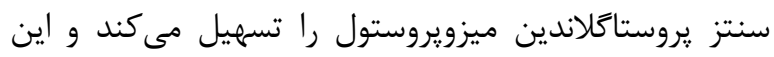

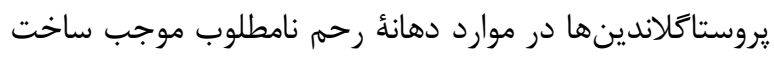

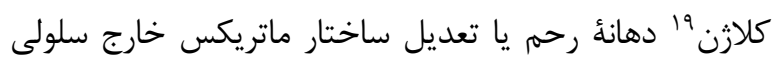

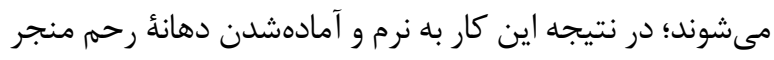
مىشود. همجنين عوارض جانبى فراوانى در استفاده از كر آنل مغربى در طول يزوهش ديده نشد.

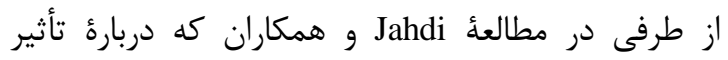

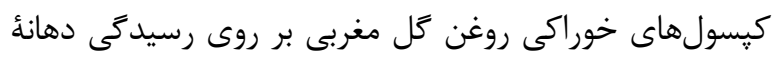

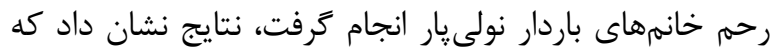
مصرف كيسولهاى روغن كل مغربى باصورت خوراكى در

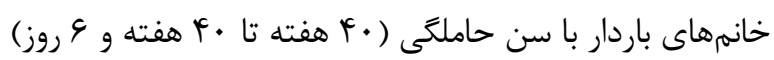

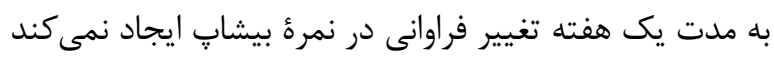

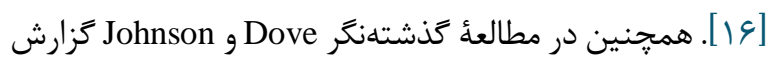

\section{${ }^{19}$. Collagen}

مجله مراقبت يرستارى و مامايى ابنسينا 
نتايج اين مطالعه نشان مىدهد كه استفاده از كِيسول وازينال روغن گل مغربى به عنوان مكمل در كنار ميزويروستول دئل

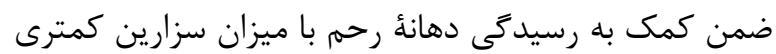

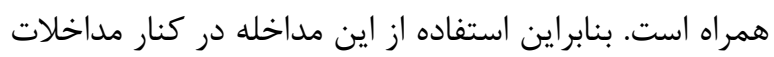

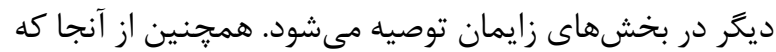
كاربرد داروهاى كياهى و طب مكمل بسيار حائز اهميت است ندان

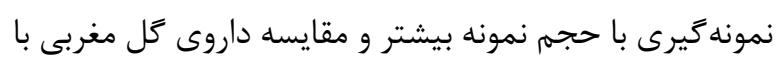
ديخر داروهاى كياهى و شيميايى و همجنين استفاده از ديكر نماني روشهاى غيردارويى توصيه مىشود.

\section{سياسگزارى}

اين مقاله نتايج پاياننامؤ مقطع كارشناسى ارشد دانشكاه

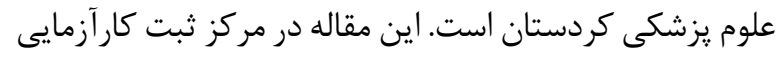
بالينى با كد (IRCT20180224038846N1) و در دمريتئ اخلاق با كد ir.muk.rec.1396/36 ثبت شد. بد بدينوسيله

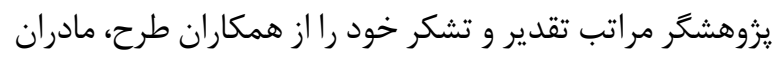

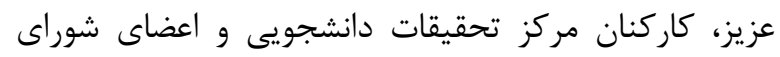

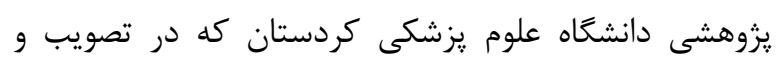

اجراى اين طرح همكارى صميمانه داشتند، ابراز مى دارد.

$$
\text { تعارض در منافع }
$$

بين نويسندكان هيجگَّنه تعارضى در منافع وجود ندارد.

$$
\text { منابع مالى }
$$

منابع مالى اين مطالعه توسط دانشگاه علوم بزشكى كردستان تأمين شده است.
رحمى و علايم حياتى مادر بعد از مداخله ديده نشد و همجنين

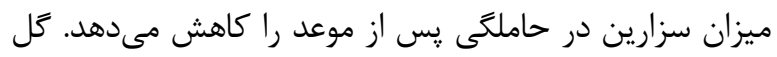

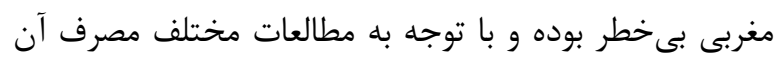

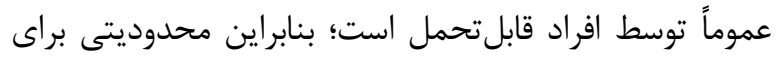

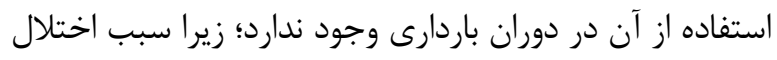

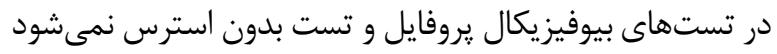

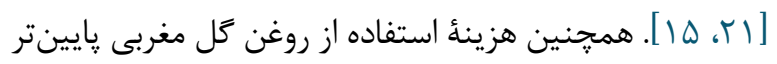

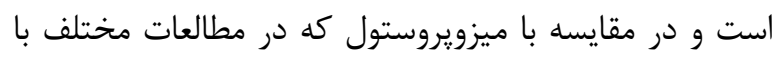
عوارض جانبى مانند تاكى سيستول رحمى، دكولمان، نياز به

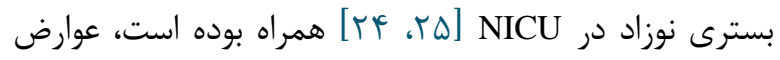

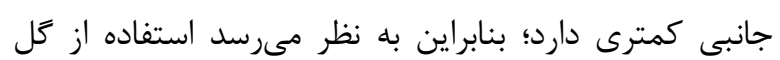

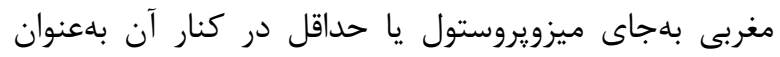

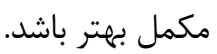

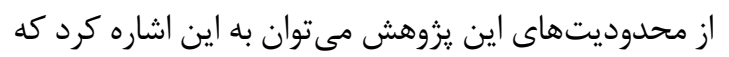

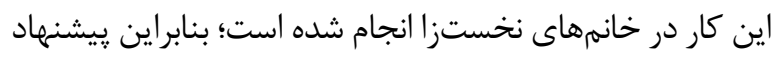

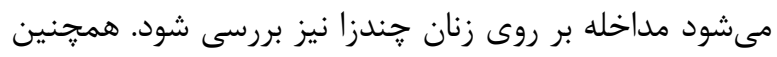

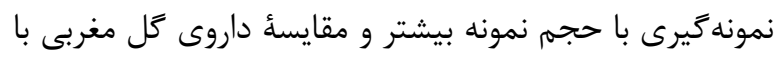

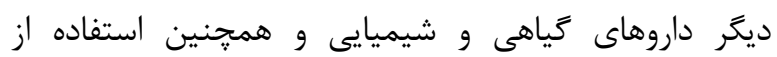

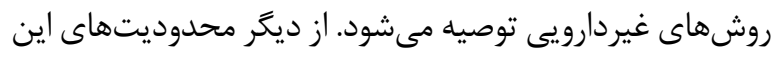

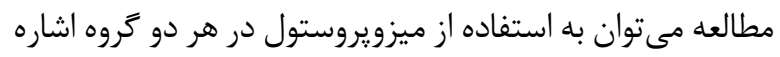

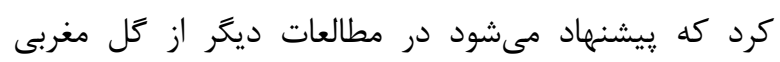

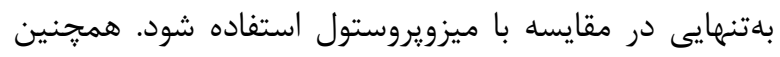

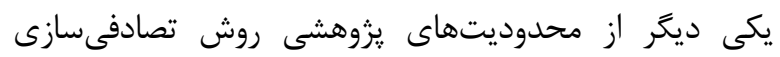

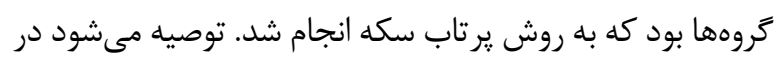

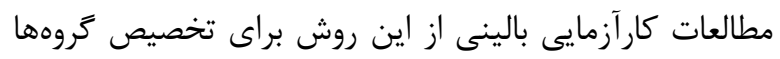
استفاده نشود. نتبجهد تيبرى

\section{References}

1. Cunningham, Leveno, Bloom, Spong, Dashe, Hoffman, Casey, Sheffield. Williams Obstetrics.24th.Tehran: Arjmand Pub: 2018.

2. Shahali S, Khatami F, Abbaspoor Z, Gheraghian B. The effect of vaginal evening primrose capsule on cervical ripening in nulliparous women with postterm pregnancy: A clinical trial. IJOGI. 2018;21(8):30-8.

3. Ministry of health and medical education. national guide to midwifery and childbirth services. Tehran, 2017.Retreived from https://behdasht.gov.ir.

4. Rezaie M, Seyedoshohadaei F, Nayebi M. Comparison of oral and vaginal prescription of misoprostol in labor induction of post-term pregnancies. Horizon Med Sci. 2016;22(2):103-9. [DOI:10.18869/acadpub.hms.22.2.103]

5. Eslamian L, Shahsavari H. Management and outcome of prolonged pregnancies in Shariati university hospital. Tehran Univ Med J. 2008; 65(12):48-54.

6. Hajivandi L, Montazeri S, Irvani M, Oliyai A, Haghighi zade M. Investigating the Effect of 
Intramuscular Dexamethas on Duration of Labor in Post Date Pregnancy. JSSU. 2013; 21 (5):555-63.

7. Teymori B, GHasemi M, Sakhavar N, Khajenouri S. Comparison of Vaginal Trinitroglycerin (TNG) and Vaginal Misoprostol in Cervical Ripening at term pregnancy. Iran. J. Obstet. Gynecol. Infertil. 2018; 20(11): 8-14. [Persian]

8. PonMalar J, Benjamin SJ, Abraham A, Rathore S, Jeyaseelan V, Mathews JE. Randomized doubleblind placebo controlled study of preinduction cervical priming with $25 \mu \mathrm{g}$ of misoprostol in the outpatient setting to prevent formal induction of labour. Arch Gynecol Obstet. 2017;295(1):33-8. [DOI:10.1007/s00404-016-4173-z] [PMID]

9. Husain S, Husain S, Izhar R. Oral misoprostol alone versus oral misoprostol and Foley's catheter for induction of labor: A randomized controlled trial. J Obstet Gynaecol Res. 2017;43(8):1270-7. [DOI:10.1111/jog.13354] [PMID]

10. Keshavarzi F, Nankoli A, Rezaie M, Fakheri T, Jalilian N, Mohammadi N, Lashni N, Khashay A. Compare amniotic infusion of normal saline and hydrocortisone with suppositories prostaglandin E2 for termination of pregnancy. J Birjand Univ Med Sci. 2012;19(2):132-139.

11. Jalilian N, Tamizi N, Rezaei M. The effect of vaginal Misoprostol and intravenous Oxytocin for labor induction, J Kermanshah Univ Med Sci. 2010 ; 14(3):e79473.

12. Sharifzadeh, F., Abbasi Dezfouli, G., Moeini Chaghervand, M., Azad, Z. Comparison of the efficacy of Glyceryl trinitrate and Misoprostol on cervical ripening for curretage in pregnant women at first trimester. Iran J Obstet Gynecol Infertil, 2015; 18(174): 6-11. [DOI:10.22038/ijogi.2015.6371]

13. Inal HA, Inal ZH, Tonguc $\mathrm{E}$, Var T. Comparison of vaginal misoprostol and dinoprostone for cervical ripening before diagnostic hysteroscopy in nulliparous women. Int $\mathbf{J}$ Fertil Steril. 2015;103(5):1326-31.

[DOI:10.1016/i.fertnstert.2015.01.037] [PMID]

14. Alinejati S, Mallah F. Comparing the Efficacy and Side Effects of Trans-Cervical Catheter and Vaginal Misoprostol on Cervical Ripening. Alborz Univ Med J. 2016;5(3):149-56. [Persian] [DOI:10.18869/acadpub.aums.5.3.149]

15. Alamiherandi R, Karamali M, Moieni A Comparison of efficacy and side effects of oral misoprostol with oxytocin to induce labor in term pregnancy. J North Khorasan Univ Med Sci. 2012; 4(3): 303-09. [Persian] [DOI:10.29252/jnkums.4.3.303]

16. Jahdi F, Kalati M, Kashanian M, Naseri M, Haghani H. Effect of oral evening primrose capsules on ripening of the cervix in nulliparous iranian pregnant women (a randomized trial). Acta Med Mediterranea. 2016;32(Specia):1273-9. [Persian]

17. Tahermanesh K, Vahdat M, Mehdizade Kashi A, Ashouri M, Solaymani Dodaran M, Kashanian M, Alizade $\mathrm{P}$ et at. Evening Primrose Oil Effect on the Ease of Cervical Ripening and Dilatation before Operative Hysteroscopy. Thrita J. 2015; 4(3): e29876. [Persian] [DOI:10.5812/thrita.29876]

18. Fallah LT, Najafi A, Fathizadeh N, Khaledian Z. The effect of evening primrose oil on premenstrual syn. Sci J Hamadan Nurs \& Mid. 2008;10;16(1):35-45. [Persian]

19. González CA, Guerra AS, Llano RA. Behavior of cervix during pregnancy, labor and puerperium. Ginecol Obstet Mex. 2010;78(02):132-7.

20. Beigi A, Kazemipour SM, Tabarestani H. Induction of labor in term pregnancy: Sublingual versus vaginal misoprostol. Mag Tehran Uni Med Sci. 2010; 68(3): 175-81. [Persian]

21. Dove D, Johnson P. Oral evening primrose oil: Its effect on length of pregnancy and selected intrapartum outcomes in low-risk nulliparous women. J Nurs-Midwifery. 1999; 44(3): 320-4. [DOI:10.1016/S0091-2182(99)00055-5]

22. Bayles B, Usatine R. Evening primrose oil. Am Fam Physician. 2009;80(12):1405-8.

23. Nonette DN. The effectiveness of evening primrose oil gel capsule as a cervical ripening agent during labor induction as measured by bishop score on term singleton pregnant patients. Philippine J Obstet Gynecol. 2017; 41(2):1-4.

24. Abedi Asl ZH, Pordelshahri M, Amirian M, Zare $\mathrm{SH}$. Compare the effects of vaginal misoprostol and Foley catheter intracervically on cervical ripening before induction of labor at term pregnancy. Med J. 2005; 63(9): 757-63.

25. Chung JH, Huang WH, Rumney PJ, Garite TJ, Nageotte MP. A prospective randomized controlled trial that compared misoprostol, Foley catheter, and combination misoprostol-Foley catheter for labor induction. Am.J Obstet Gynecol. 2003; 189: 1031-5. [DOI:10.1067/S00029378(03)00842-1]

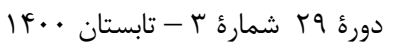

